\title{
Usulan Keamanan Sistem Informasi pada Penyelenggara Financial Technology (Fintech) Menggunakan Cobit 5 (Studi Kasus: Gandengtangan.org)
}

\author{
Oki Nurkholis ${ }^{1}$, Fitroh $^{2}$, Eri Rustamaji ${ }^{3}$
}

\begin{abstract}
Gandengtangan.org adalah salah satu perusahaan startup di bidang financial technology (fintech) yang ada di Indonesia. Gandengtangan.org menyediakan layanan pengumpulan pinjaman (crowdlending) untuk para pelaku usaha sosial atau UMKM yang ada di Indonesia. Beberapa masalah yang muncul pada penelitian ini di antaranya: (1) kerentanan penggunaan internet terutama sektor finansial yang menjadi target serangan nomor 2 terbanyak. (2) Otoritas Jasa Keuangan (OJK) juga mewajibkan untuk setiap penyelenggara fintech di Indonesia agar dapat memenuhi standardisasi mengenai keamanan informasi pada perusahaannya. (3) Belum pernah dilakukaannya evaluasi terhadap keamanan sistem informasi di Gandengtangan. (4) Terjadinya 4 kasus keamanan informasi: satu kasus terkait phising, dua kasus tentang integrasi data, dan satu kasus terkait ssl (secure socket layer). Hal ini menunjukan keamanan informasi menjadi hal yang perlu mendapatkan perhatian penting pada Gandengtangan.org. Metode penilaian yang digunakan adalah perpaduan antara Process Assessment Model (PAM) dengan COBIT 5 Life cycle. Dipilih 5 domain yang berhubungan dengan keamanan pada COBIT 5 yakni, EDM03 (Ensure Risk Optimisation), APO12 (Manage Risk), APO13 (Manage Security), BAI06 (Manage Changes), dan DSS05 (Manage Security Services). Penelitian ini menghasilkan usulan keamanan informasi yang menjadi panduan Gandengtangan.org untuk mengantisipasi kerentanan keamanan pada bisnisnya dan untuk memenuhi persyaratan dari OJK.
\end{abstract}

Keywords- Startup, Financial Technology (Fintech), Crowdlending, COBIT 5, EDM03, APO12, APO13, BAI06, DSSO5, partially achieved, process attributes.

\section{PENDAHULUAN}

andengtangan.org adalah sebuah wadah kolaborasi bagi pemilik usaha yang membutuhkan modal dengan publik yang tulus ingin membantu dengan memberikan pinjaman. Gandengtangan.org hadir untuk menjembatani keduanya agar

Received: 15 April 2019 ; Revised: 25 Mei 2019; Accepted: 1 Juli 2019

O. Nurkholis, Data Center operator di Coca Cola Amatil, Indonesia (e-mail: okinurkholis@gmail.com ).

http://journal.uinjkt.ac.id/index.php/aism dapat bergandengan tangan untuk menciptakan dampak baik Cagi Indonesia[1]. Jika dikategorikan ke dalam jenis Jperusahaan di Indonesia, Gandengtangan.org termasuk ke dalam Layanan Pinjam Meminjam Uang Berbasis Teknologi Informasi (LPMUBTI) atau Financial Technology (Fintech). Fintech adalah penyelenggara layanan jasa keuangan untuk mempertemukan pemberi pinjaman dengan penerima pinjaman dalam rangka melakukan perjanjian pinjam meminjam dalam mata uang rupiah secara langsung melalui sistem elektronik dengan menggunakan jaringan internet[2].

Perbedaan Gandengtangan dengan layanan Fintech lainnya yakni, Gandengtangan mengkhususkan layanan peminjaman mereka untuk membantu pendanaan Usaha Kecil dan Menengah (UMKM) terutama UMKM yang termasuk ke dalam Social Entreprise yang ada di Indonesia. UMKM di Indonesia sendiri merupakan salah satu penggerak roda perekonomian di Indonesia, hal ini dapat dilihat dari sumbangan UMKM yang mencapai 99,9 \% dari total pelaku usaha yang ada di Indonesia serta mampu menyediakan 97,24 \% dari total penyerapan tenaga kerja yang ada di Indonesia[3].

Namun UMKM di Indonesia masih mengalami kendala dalam masalah pendanaan. Mayoritas UMKM yang ada di Indonesia tidak cukup untuk memenuhi persyaratan untuk dapat mendapatkan pendanaan dari industri perbankan, atau dalam istilahnya disebut tidak bankable. Oleh karena itu, Gandengtangan.org hadir untuk dapat membantu masalah pendanaan untuk UMKM tersebut [4].

Dalam menjalankan usahanya Gandengtangan menggunakan konsep crowdlending [5] yang menggunakan internet sebagai salah satu komponen utama dalam menjalankannya. Selain itu Gandengtangan juga menggunakan e-money untuk para penggunanya.

Penggunaan internet dan E-Money pada Gandengtangan.org maupun penyedia layanan Fintech lainnya berpotensi untuk mengancam data dan dana dari pengguna.

F. Fitroh, Prodi Sistem Informasi, UIN Syarif Hidayatullah Jakarta, Indonesia (e-mail: fitroh@uinjkt.ac.id )

E. Rustamaji, Prodi Sistem Informasi, UIN Syarif Hidayatullah Jakarta, Indonesia (e-mail: eri.rustamaji@uinjkt.ac.id ). 
Laporan dari Symantech menyebutkan bahwa sektor finansial menjadi sasaran nomor 2 terbanyak yang diserang untuk pencurian data dan informasi pribadi[6]. Selain itu salah satu situs Crowdfunding besar, Kickstarter, melaporkan bahwa mereka mengalami pencurian data para penggunanya[7]. Dengan memiliki data pengguna, orang lain dapat dengan mudah melakukan perubahan atau bahkan mencuri dana pengguna, misalnya melalui data kartu kreditnya.

Dalam Gandengtangan.org sendiri telah mengalami 4 kasus terkait dengan keamanan informasi, satu kasus phising, satu kasus terkait sertifikat SSL, dan kasus lainnya terkait integrasi data. Gandengtangan.org pun belum pernah melakukan audit keamanan atau pun menerapkan suatu standar keamanan informasi dalam perusahaan. Gandengtangan.org yang termasuk ke dalam salah satu penyelenggara Fintech harus memenuhi persyaratan yang ditetapkan oleh OJK tersebut untuk memenuhi perizinan sebagai penyelenggara Fintech yang berpayung hukum Republik Indonesia. Selain itu, penerapan keamanan informasi di Gandengtangan.org yang belum memadai juga perlu ditingkatkan untuk perkembangan bisnis mereka. Oleh karena itu, penelitian ini dilakukan untuk mengetahui tingkat kapabilitas keamanan informasi dan memberikan rekomendasi untuk meningkatkan kapabilitas keamanan informasi di Gandengtangan.org. Penelitian ini dilakukan berdasarkan pada Control Objectives for Information and Related Technology 5 (COBIT 5).

Framework COBIT 5 dipilih karena keunggulannya dibandingkan dengan framework keamanan sistem informasi lainnya, yakni memenuhi 11 kriteria framework keamanan sistem informasi [8] dan memiliki keunggulan dalam hal metrik, tolak ukur, dan audit[9].

\section{Metode PENELITIAN}

Dalam penelitian ini, penulis memilih metode penelitian deskriptif. Karena penelitian ini bertujuan untuk mengetahui kapabilitas keamanan suatu sistem informasi, maka metode penilitian deskriptif cocok untuk digunakan.

Penelitian ini menggunakan metode penelitian deskriptif dengan menggunakan survey [10]. Metode survei digunakan untuk mempelajari sampel dari suatu populasi dan dari teknikteknik pengumpulan data survei terkait, seperti kuesioner dan metode-metode untuk meningkatkan akurasi dari survei. Dalam penelitian ini, metode penilaian deskriptif dengan survei digunakan untuk mengumpulkan informasi tentang variabelvariabel penelitian di atas.
Variabel pada penelitian ini adalah pada domain Evaluate, Direct, and Monitor (EDM); Align, Plan, and Organize (APO); Build, Acquire, and Implement (BAI); dan Deliver, Service, and Support (DSS) yakni pada proses EDM03 (Ensure Risk Optimisation) dan APO12 (Manage Risk), APO13 (Manage Security), BAI06 (Manage Changes), dan DSS05 (Manage Security Services).

Penulis menggunakan gabungan antara siklus hidup implementasi pada framework COBIT 5 dan assessor guide pada Process Assessment Model (PAM) COBIT 5. Tahapan proses terdapat pada gambar 1 dibawah ini.

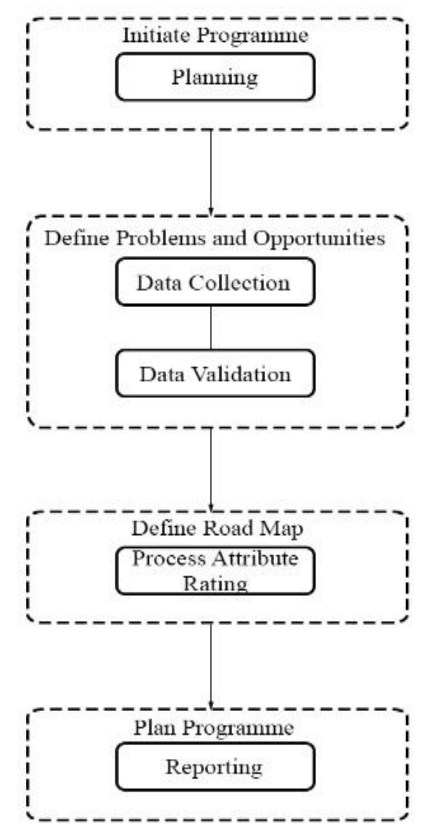

Gambar 1. Tahapan Proses Penilaian Tingkat Kapabilitas.

\section{HASIL DAN PEMBAHASAN}

Untuk melakukan proses penilaian dari tingkat kapabilitas keamanan pada Gandengtangan.org dimulai dengan melaksanakan tahap inisiasi. Pada tahap ini penulis melakukan wawancara terhadap pihak Gandengtangan.org untuk mengetahui keadaan mengenai keamanan informasi pada Gandengtangan.org. Dari hasil wawancara tersebut kemudian penulis menyusun rencana untuk pengambilan data dengan menggunakan instrumen kuesioner yang sudah dipetakan sesuai dengan RACI chart pada COBIT 5.

\section{A. Perhitungan Tingkat Kapabilitas}

Pada tahap ini akan dimulai dengan menjelaskan mengenai hasil jawaban kuesioner yang sudah diisi oleh para responden terkait pada proses EDM03 (Ensure Risk Optimisation), APO12 (Manage Risk), APO13 (Manage Security), BAI06 (Manage Changes), DSS05 (Manage Security Services). Hasil rekapitulasi ini akan memberikan gambaran mengenai keadaan aktual (as is) perusahaan serta kondisi ekspektasi (to be) yang diinginkan oleh perusahaan sehingga dapat dilihat gap yang ada untuk menjadi acuan dalam memberikan rekomendasi kepada 
perusahaan. Hasil perhitungan nilai kapabilitas di uraikan pada table 1 dan dilustrasikan pada gambar 2.

Tabel 1.

Hasil Perhitungan Nilai Kapabilitas
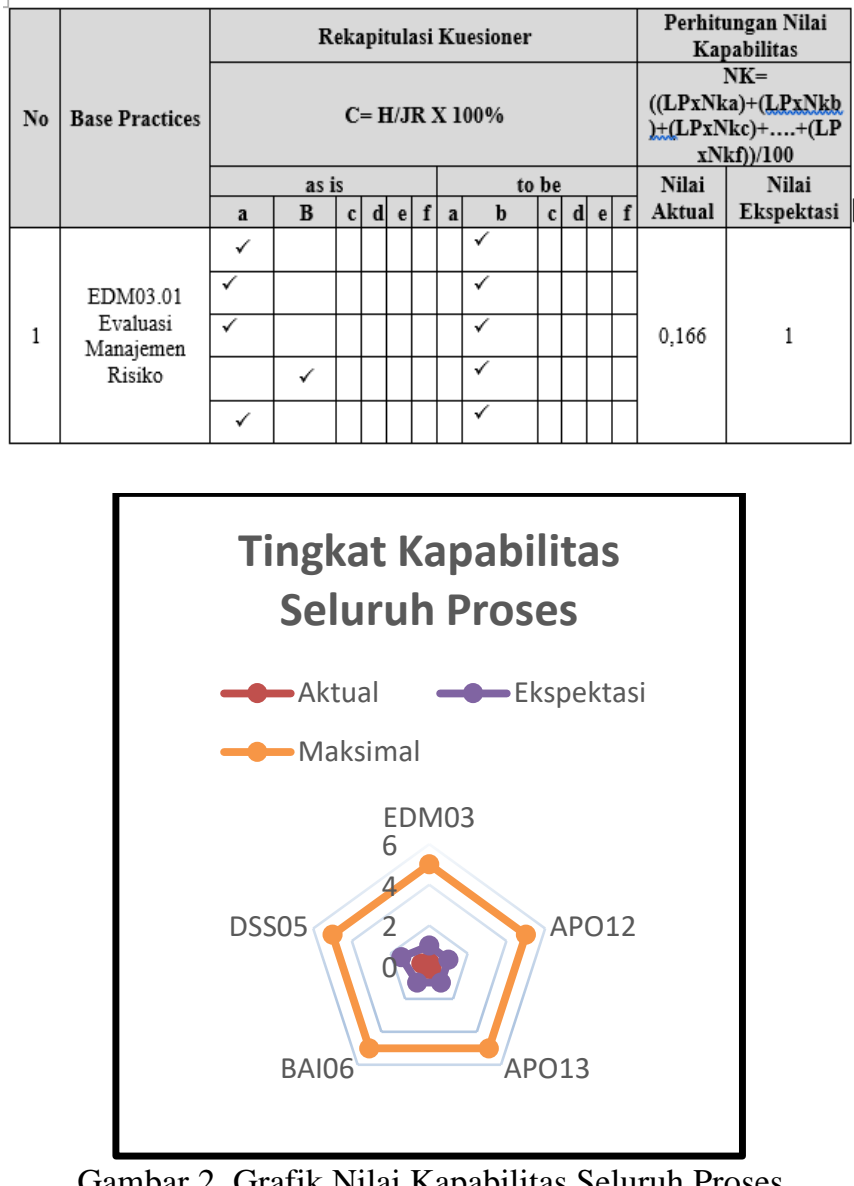

Gambar 2. Grafik Nilai Kapabilitas Seluruh Proses

Penulis mendapatkan tingkat kapabilitas aktual dan tingkat kapabilitas ekspektasi untuk semua proses pada gambar 2 . sebagai berikut:

1) EDM03 (Ensure Risk Optimisation) berada pada level 0 (incomplete process) untuk tingkat kapabilitas aktual dan berada pada level 1 (performed process) untuk tingkat kapabilitas ekspektasi.

2) APO12 (Manage Risk) berada pada level 0 (incomplete process) untuk tingkat kapabilitas aktual dan berada pada level 1 (performed process) untuk tingkat kapabilitas ekspektasi.

3) APO13 (Manage Security) berada pada level 0 (incomplete process) untuk tingkat kapabilitas aktual dan berada pada level 1 (performed process) untuk tingkat kapabilitas ekspektasi.

4) BAIO6 (Manage Changes) berada pada level 0 (incomplete process) untuk tingkat kapabilitas aktual dan berada pada level 1 (performed process) untuk tingkat kapabilitas ekspektasi.

5) DSSO5 (Manage Security Services) berada pada level 0 (incomplete process) untuk tingkat kapabilitas aktual dan berada pada level 1 (performed process) untuk tingkat kapabilitas ekspektasi.

\section{B. Define Roadmap}

Pada tahap sebelumnya sudah dilakukan proses perhitungan untuk mendapatkan nilai kapabilitas dan tingkat kapabilitas baik aktual maupun ekspektasi dari semua proses pada penelitian ini. Hasil tersebut bagaimanapun didapatkan berdasarkan pada pandangan perusahaan yakni, berasal dari jawaban kuesioner oleh para responden sedangkan COBIT 5 menekankan pada evidence based untuk menetapkan tingkat kapabilitas dari suatu proses. Maka hasil perhitungan tersebut masih belum dapat dijadikan sebagai hasil final dari tingkat kapabilitas perusahaan.

Oleh Karena itu, pada tahap define road map ini penulis akan melakukan penelusuran untuk setiap pemenuhan syaratsyarat atau atribut-atribut pencapaian level dalam model kapabilitas COBIT 5. Proses penelusuran bukti ini berdasarkan pada process assessment model (PAM) yang ada pada COBIT 5. Tingkat kapabilitas pada proses penelusuran ini akan ditentukan melalui pencapaian atribut-atribut di COBIT 5. Terlampir pada table 2 dibawah ini.

\section{Tabel 2.}

Contoh Tabel Pencapaian Atribut

\begin{tabular}{|c|c|c|c|c|}
\hline Base Practices & Work Products & Exist & Evidence & Skor \\
\hline \multirow{3}{*}{$\begin{array}{l}\text { EDM03.01 } \\
\text { Evaluasi } \\
\text { Manajemen } \\
\text { Risiko }\end{array}$} & $\begin{array}{l}\text { Pedoman Ambang Batas } \\
\text { Risiko }\end{array}$ & $\mathrm{X}$ & $\mathrm{x}$ & \multirow{3}{*}{$0 \%$} \\
\hline & $\begin{array}{l}\text { Dokumen Ambang Batas } \\
\text { Risiko yang Sudah Disetujui }\end{array}$ & $\mathrm{X}$ & $\mathrm{x}$ & \\
\hline & $\begin{array}{l}\text { Evaluasi Kegiatan } \\
\text { Manajemen Risiko }\end{array}$ & $\mathrm{X}$ & $\mathrm{x}$ & \\
\hline \multirow{3}{*}{$\begin{array}{l}\text { EDM03.02 } \\
\text { Mengarahkan } \\
\text { Penggunaan } \\
\text { Manajemen } \\
\text { Risiko }\end{array}$} & Peraturan Manajemen Risiko & $\mathrm{X}$ & $\mathrm{x}$ & \multirow{3}{*}{$0 \%$} \\
\hline & $\begin{array}{l}\text { Objektif kunci dari } \\
\text { Manajemen Risiko }\end{array}$ & $\mathrm{X}$ & $\mathrm{x}$ & \\
\hline & $\begin{array}{l}\text { Pengukuran Manajemen } \\
\text { Risiko yang sudah Disetujui }\end{array}$ & $\mathrm{X}$ & $\mathrm{x}$ & \\
\hline \multirow{2}{*}{$\begin{array}{l}\text { EDM03.03 } \\
\text { Mengawasi } \\
\text { Manajemen } \\
\text { Risiko }\end{array}$} & $\begin{array}{l}\text { Perbaikan untuk Mengetahui } \\
\text { Kekurangan Manajemen } \\
\text { Risiko }\end{array}$ & $\mathrm{X}$ & $\mathrm{x}$ & \multirow{2}{*}{$0 \%$} \\
\hline & $\begin{array}{l}\text { Pelaporan Manajemen } \\
\text { Risiko pada Pemimpin } \\
\text { Perusahaan }\end{array}$ & $\mathrm{X}$ & $\mathrm{x}$ & \\
\hline \multicolumn{4}{|c|}{ Rata-rata Skor } & $0 \%$ \\
\hline
\end{tabular}

Selanjutnya penulis menemukan bahwa tingkat kapabilitas aktual perusahaan yang ditunjukkan dari hasil perhitungan kuesioner sudah sesuai tingkat dengan kapabilitas aktual yang berdasarkan dengan syarat pemenuhan atribut pada process assessment model yang digunakan pada framework COBIT 5. Dengan begitu, penulis dapat menyusun rekomendasi yang sesuai dengan framework COBIT 5 untuk perusahaan. Rekomendasi yang diberikan akan membantu perusahaan untuk dapat memenuhi standar yang ditetapkan pada framework COBIT 5, agar sesuai dengan level ekspektasi yang dihasilkan pada kuesioner

\section{KesimpUlan}

Berdasarkan hasil penelitian dan identifikasi masalah pada penelitian ini, berikut kesimpulan yang dapat penulis jelaskan:

http://journal.uinjkt.ac.id/index.php/aism 
A. Dengan menggunakan hasil penelitian ini Gandengtangan.org mempunyai panduan berupa usulan keamanan informasi berdasarkan framework COBIT 5 untuk melindungi komponen utama bisnisnya yakni, penggunaan internet yang rentan akan masalah keamanan informasi.

B. Dengan menggunakan hasil penelitian ini Gandengtangan.org memiliki panduan berupa usulan keamanan informasi berdasarkan framework COBIT 5 untuk dapat memenuhi persyaratan yang diwajibkan oleh OJK untuk para penyelenggara Fintech di Indonesia terkait standar keamanan: kerahasiaan, keutuhan, dan ketersediaan data pengguna; dan riwayat rekam jejak audit.

C. Dengan menggunakan hasil penelitian ini Gandengtangan.org sudah melakukan evaluasi terhadap keamanan sistem informasi pada perusahaan dengan berdasarkan pada framework COBIT 5.

Berdasarkan hasil dari tingkat kapabilitas pada kelima proses di penelitian ini (EDM03, APO12, APO13, BAI06, dan DSS05) dan gap dengan tingkat kapabilitas ekspektasi, penulis menyimpulkan Gandengtangan.org masih berada pada tahap awal dalam penerapan keamanan informasi berdasarkan dengan framework COBIT 5. Perusahaan masih memiliki banyak kekurangan untuk memenuhi peryaratan pada level 1 (performed process) yang menjadi tingkatan awal dari indikator tingkat kapabilitas yang digunakan pada COBIT 5.

\section{REFERENSI}

[1] "Tentang Kami," in gandengtangan.org, ed, 2017.

[2] Peraturan Otoritas Jasa Keuangan Tentang Layanan Pinjam Meminjam Uang Berbasis Teknologi Informasi. Jakarta: OJK Republik Indonesia 2016.
[3] H. Septian, "Edukasi Tentang Pengelolaan dan Pengembangan Usaha Kecil Menengah (UKM) Bagi Pedagang Kaki Lima di Jagakarsa Jakarta Timur," vol. 1, no. 1, pp. 31-42, 2018.

[4] G. Andini, "Faktor-faktor yang menentukan keputusan pemberian kredit usaha mikro kecil dan menengah (UMKM) pada lembaga keuangan mikro peer to peer lending," Jakarta: Fakultas Ekonomi dan Bisnis UIN Syarif Hidayatullah Jakarta, 2017.

[5] A. Bellami, "Analisis Perilaku Beralih Layanan Pembiayaan Berbasis Financial Technology (Crowdlending) Dengan Pendekatan Push-PullMooring," 2018.

[6] P. Wood, B. Nahorney, K. Chandrasekar, S. Wallace, and K. Haley, Tech. Rep., "Symantec internet security threat report," vol. 21, 2016.

[7] "Post Page," in edition.cnn.com, ed, 2017.

[8] F. H. Alqahtani, "Developing an information security policy: A case study approach," vol. 124, pp. 691-697, 2017.

[9] A. Abbas, S. U. Khan, and H. Informatics, "A review on the state-of-theart privacy-preserving approaches in the e-health clouds," vol. 18, no. 4, pp. 1431-1441, 2014.

[10] M. Hendayun, "Tata Kelola pada Perguruan Tinggi Menggunakan Control Objective for Information \& Related Technology (COBIT) 5," vol. 3, no. 1, 2017. 